\title{
Reply to comment on "Geochemical heterogeneity and isotope geochemistry of natural attenuation processes in a gasoline-contaminated aquifer at the Hnevice site, Czech Republic": report published in Hydrogeology Journal (2007) 15: 961-976, by Barbora Topinkova, Kamil Nesetril, Josef Datel, Ondrej Nol, Petr Hosl
}

\author{
Barbora Topinkova
}

Keywords Conceptual models $\cdot$ Hydrochemistry $\cdot$ Reply

The authors of the subject article (Topinkova et al. 2007) are pleased to respond to the Comment as follows:

The indication of zones in Fig. 5 of the subject article, in accordance with the text, should be as follows: Zone I is Background, Zone II is Reoxidation zone, Zone III is Plume core, and Zone IV is Plume fringe. This mistake arose during the creation of Fig.5 and the authors greatly apologize for that.

The presence of secondary magnetite is questioned in the Comment because of highly alkaline groundwater and precipitation of Fe-carbonates. These conditions and the secondary carbonate precipitation are typical for the plume core but the origin of the secondary magnetite was discussed with respect to the plume fringe. Iron (hydr) oxides firstly precipitate in the zone of the contaminant plume and are converted over the years via bacterial processes to goethite, hematite, or magnetite, depending on the presence of specific microbial strains and Fe(II) concentrations in groundwater. These processes are described in papers by, for example, Hansel et al. (2003)

The difference between $\delta^{34} \mathrm{~S}$ in samples PJ500 (35.8\%o) and PJ519/5 (36\%) is discussed in the subject article on page 973 . This difference is well within the margin of error of the analytical method. The authors of

Received: 31 October 2008 /Accepted: 2 April 2009

Published online: 5 May 2009

(C) Springer-Verlag 2009

B. Topinkova $(\bullet)$

Department of Hydrogeology, Faculty of Science,

Charles University of Prague,

Albertov 6, 128 43, Prague 2, Czech Republic

e-mail: barboratopinkova@seznam.cz

Tel.: +420-234-607439 the Comment consider the explanation of the anomalous $\delta^{34} \mathrm{~S}$ in the plume core impossible because of the $\mathrm{pH}$ range, but extended mineralogical research found a large amount of iron and manganese precipitates that could create a wide surface feasible for sorption. Over and above this explanation could be the consequence of local changes of advective flow. These local inhomogenities were confirmed by granular analysis in the studied part of the aquifer. Both alternatives are discussed in the subject article.

The authors of the subject article are the authors of the basic draft of the conceptual model that was presented at the CORONA project meeting in autumn of 2003. The report of Topinkova et al. (2007) is based on data that were collected by all of its authors during field and laboratory work in 2002-2004. The report was submitted for publication in Hydrogeology Journal on the April 6, 2005. The article cited in the Comment (Vencelides et al. 2007) was submitted for publication on the December 8, 2005, and uses all data and background knowledge presented in the report of Topinkova et al. (2007). These background data were obtained during the CORONA international project and the authors of both articles were members of the same research group. Thus all comments about authorship are irrelevant.

\section{References}

Hansel CM, Benner SG, Neiss J, Dohnalkova A, Kukkadapu RK, Fendorf M (2003) Secondary mineralization pathways induced by dissimilatory iron reduction of ferrihydrite under advective flow. Geochim Cosmochim Acta 67:2977-2992

Topinkova B, Nesetril K, Datel J, Nol O, Hosl P (2007) Geochemical heterogeneity and isotope geochemistry of natural attenuation processes in a gasoline-contaminated aquifer at the Hnevice site, Czech Republic. Hydrogeol J 15:961-976

Vencelides Z, Sracek O, Prommer H (2007) Modelling of iron cycling and its impact on the electron balance at a petroleum hydrocarbon contaminated site in Hnevice, Czech Republic. J Contam Hydrol 89:270-294 